\title{
Dopamine concentrations and dopamine receptor gene expression in emotion-related brain structures of female adult rats exposed to stress of chronic isolation from weaning
}

\author{
Peter Karailiev ${ }^{1}$, Natasa Hlavacova ${ }^{1}$, Pavol Chomanic ${ }^{1,2}$, Igor Riecansky ${ }^{3,4}$ and Daniela Jezova ${ }^{1}$ \\ ${ }^{1}$ Institute of Experimental Endocrinology, Biomedical Research Center, Slovak Academy of Sciences, Bratislava, Slovakia \\ ${ }^{2}$ Department of Pharmacology and Toxicology, Faculty of Pharmacy, Comenius University in Bratislava, Bratislava, Slovakia \\ ${ }^{3}$ Institute of Normal and Pathological Physiology, Centre of Experimental Medicine, Slovak Academy of Sciences, Bratislava, \\ Slovakia \\ ${ }^{4}$ Department of Cognition, Emotion and Methods in Psychology, Faculty of Psychology, University of Vienna, Vienna, Austria
}

\begin{abstract}
It is known that early-life stress events induce profound consequences on emotional brain regions including amygdala, involved in emotional processing and the ventral tegmental area (VTA), which contains neuron cell bodies of the mesolimbic dopaminergic system. The aim of this study is to test the hypothesis that stress induced by long-term social isolation from weaning in female rats is associated with alterations in amygdalar dopamine receptor gene expression and VTA dopamine concentrations. Rats were weaned on postnatal day 21 and then exposed to stress of chronic isolation for 9 weeks. Control animals were housed socially. Amygdalar dopamine $\mathrm{D}_{1}$ but not $\mathrm{D}_{2}$ receptor gene expression was decreased in isolated rats compared to controls. Dopamine concentrations in the VTA were enhanced following chronic isolation. A negative correlation was observed between amygdalar $\mathrm{D}_{1}$ gene expression and dopamine concentrations in the VTA. In conclusion, a reduction of dopamine $\mathrm{D}_{1}$ receptor gene expression in the amygdala in response to stress induced by chronic isolation in female rats was accompanied by an increase in dopamine concentration in the VTA. Further studies are needed to understand the physiological significance, if any, of negative association of amygdalar dopamine receptor $\mathrm{D}_{1}$ gene expression and dopamine concentrations in the VTA.
\end{abstract}

Key words: Amygdala - Ventral tegmentum - Neurodevelopment - Long-term stress - Dopamine - Rats

\section{Introduction}

It is well known that early-life stress events, e.g. lack of care, child abuse or emotional neglect, induce profound consequences on the organization of different brain circuits, such as emotion-related brain structures underlying stress-coping and adaptation (Daskalakis et al. 2013). The general consensus is that a history of negative early-life events is coupled with increased emotional responding in which the main

Correspondence to: Daniela Jezova, Laboratory of Pharmacological Neuroendocrinology, Institute of Experimental Endocrinology, Biomedical Research Center, Slovak Academy of Sciences, Dubravska cesta 9, 84505 Bratislava, Slovakia

E-mail: daniela.jezova@savba.sk brain structure involved is amygdala and with impairment of cognitive performance. An important role is played by the ventral tegmental area (VTA), which contains cell bodies of neurons of the mesolimbic dopaminergic system (Douma and de Kloet 2020).

Dopamine acts on dopamine receptors to regulate motor and non-motor functions in a specific manner. Dopamine receptors are classified into 2 families, D1-like receptors and D2-like receptors, on the basis of pharmacologic properties and the ability to regulate the second messenger cyclic adenosine monophosphate (cAMP) generation (Jaber et al. 1996). $D_{1}$-like excitatory receptors ( $D_{1}$ and $D_{5}$ receptors) are $G_{s}$-protein coupled receptors that activate adenylyl cyclase to produce cAMP with subsequent activation of protein kinase $\mathrm{A}(\mathrm{PKA})$. The $\mathrm{D}_{2}$-like 
inhibitory receptors $\left(D_{2}, D_{3}\right.$, and $D_{4}$ receptors) are $\mathrm{G}_{\mathrm{i}^{-}}$ protein coupled receptors, which attenuate the activity of adenylyl cyclase and inhibit the production of cAMP and PKA (Beaulieu et al. 2015).

An elevated dopaminergic function was described in the amygdala of male Wistar rats that underwent early maternal deprivation. No simultaneous changes in the gene expression of dopamine $D_{1}$ and $D_{2}$ receptors were observed (Rentesi et al. 2013). Chronic isolation from weaning in a rat strain prone to enhanced acquisition of ethanol seeking behaviour (Fawn-Hooded rats) led to increased dopamine $\mathrm{D}_{2}$ receptor density in the central amygdala (Djouma et al. 2006). To our knowledge, no other data is available on the expression of dopamine receptors in the amygdala of rodents subjected to early life stressors. A decrease in dopamine $\mathrm{D}_{2}$ receptor gene and/or protein expression was observed in the amygdala of adult male rats exposed to repeated restraint and chronic mild stress in combination with low anxiety trait and amphetamine treatment, respectively (Lehner et al. 2018; Kolosowska et al. 2019). Repeated social defeat stress of adult male mice failed to induce alterations of amygdalar $\mathrm{D}_{2}$ expression but led to an increase in dopamine $D_{1}$ receptor expression in susceptible mice (Huang et al. 2016).

The consequences of long-term stress during development in the form of social isolation of male rats starting from weaning were found to be modified by a lesion of the VTA (Lebedev et al. 1995). In another study with a similar model of social isolation, the authors observed a decrease of dopamine levels in the amygdala but no changes in the VTA (Wang et al. 2012). It is known that dopamine concentrations in the VTA increase in response to acute stressors. Less information is available in respect to repeated and chronic stress. Chronic restraint and repeated social defeat resulted in an increase in spontaneous and burst firing of VTA dopamine neurons (Holly and Miczek 2016). Electrophysiological studies showed that prenatal exposure to maternal immune activation caused an increase in the excitability of dopamine neurons in male, but not in female rats (Csatlosova et al. 2019).

Table 1. Oligonucleotide sequences used in quantitative PCR

\begin{tabular}{lll}
\hline Gene & Sense & Sequence $5^{\prime} \rightarrow 3^{\prime}$ \\
\hline UQCRFS & Forward & ACAGTGGGCCTGAATGTTCC \\
-reference gene & Reverse & CACGGCGATAGTCAGAGAAGTC \\
\cline { 2 - 3 } TfR1- & Forward & ATACGTTCCCCGTTGTTGAGG \\
reference gene & Reverse & GGCGGAAACTGAGTATGGTTGA \\
\cline { 2 - 3 } $\begin{array}{l}\text { Dopamine } D_{1} \\
\text { receptor }\end{array}$ & Forward & CGAACTGTATGGTGCCCTTC \\
Dopamine $D_{2}$ & Reverse & GATGGAATCGATGCAGAATG \\
receptor & Reverse & GCAGTCGAGCTTTCAGAGCC \\
\hline
\end{tabular}

Brain disorders related to stress and dopamine neurotransmission, such as addictive behaviours, anxiety and depressive disorders are female prevalent (Bangasser and Valentino 2014). Moreover, females showed higher dopamine turnover in the VTA compared to males (Becker and Chartoff 2019). The aim of the present study is to test the hypothesis that stress induced by long-term social isolation during development in female rats is associated with alterations in amygdalar dopamine receptor gene expression and VTA dopamine concentrations.

\section{Materials and Methods}

\section{Animals and experimental design}

Female Sprague-Dawley rat pups born and handled as described previously (Chmelova et al. 2019a, 2019b) were weaned on postnatal day 21 . The pups were exposed to stress of chronic social isolation (housing of one rat per cage) or control conditions with social rearing (housing of 3 rats per cage) for 9 weeks. The details on animals and experimental design were reported previously (Chmelova et al. 2019a, 2019b). All experimental procedures were approved (approval number Ro-420/15-221) by the Animal Health and Animal Welfare Division of the State Veterinary and Food Administration of the Slovak Republic.

\section{Tissue collection}

On postnatal day 85 , the animals were decapitated and the brains were procured from the skulls. The amygdala and the VTA were removed, stored in liquid nitrogen and later stored at $-70^{\circ} \mathrm{C}$ until analysed.

\section{Neurochemical analyses}

Gene expression of the dopamine receptors $\mathrm{D}_{1}$ and $\mathrm{D}_{2}$ was measured in the amygdala by quantitative polymerase chain reaction (qPCR). Total RNA was extracted using TRI Reagent $^{\circ}$ (Invitrogen, USA) according to the manufacturer's protocol. The mRNA was transcribed into cDNA with the use of ProtoScript First Strand cDNA Synthesis Kit (NewEngland Biolabs, USA). Gene expression was quantified as described previously (Balagova et al. 2019). Primer BLAST NCBI software was used to design primers specific for studied genes (Table 1).

Dopamine concentrations in the VTA were measured by enzyme-linked immunosorbent assay (Dopamine Research ELISA $^{\text {TM }}$ kit; BA E-5300, Nordhorn, Germany) in accordance with manufacturer's instructions. The tissues of VTA were homogenized in $\mathrm{HCl}(0.01 \mathrm{~N})$ with sodium metabisulfite (4 mM) and EDTA (1 mM). After centrifugation the 
supernatants were collected for measurements. The assay involved special Cis-diol affinity gel extraction, acylation and enzymatic conversion.

\section{Statistical analysis}

The obtained data was first checked for distributional properties by Shapiro Wilk's test and subsequently winsorized using a $15 \%$ two-tailed quantile trimming to treat the identified outlying observations $(1.5 \times$ interquartile range rule) when appropriate. Dopamine receptor $\mathrm{D}_{1}$ and $\mathrm{D}_{2}$ gene expression and dopamine concentration data was analyzed by $t$-test for independent groups. The Pearson correlation was used to assess the relationship between the parameters measured. Results are expressed as means \pm SEM. The level of significance was set at $p<0.05$. Data analysis was performed using Statistica 7 software (Statsoft Inc, USA).

\section{Results}

Statistical analysis by Student $t$-test showed significantly lower concentrations of mRNA coding for dopamine receptor $\mathrm{D}_{1}$ in the amygdala $\left(\mathrm{t}_{22}=-2.64, p<0.05\right)$ in stressed rats compared to controls (Fig. 1A). The comparison of concentrations of mRNA coding for dopamine receptor $\mathrm{D}_{2}$ in the amygdala with those in controls by Student $t$-test did not show any statistical difference (Fig. 1B). Statistical analysis by Student $t$-test showed significantly higher concentrations of dopamine in the VTA $\left(\mathrm{t}_{21}=-2.74, p<0.05\right)$ in stressed rats compared to controls (Fig. 2A).

Pearson correlation analysis (Fig. 2B) showed a significant negative correlation between gene expression of amygdalar dopamine receptor $\mathrm{D}_{1}$ expressed in arbitrary units and dopamine concentrations in the VTA $(r=-0.4968, p<0.05)$. When the correlation analysis was performed in each experimental group separately, no significant correlation was revealed in non-stressed controls $(r=-0.2014, p=0.553)$, while there was a marginal significance in the group of rats subjected to the stress of social isolation $(\mathrm{r}=-0.5592, p=$ 0.059). No other significant correlations were found.

\section{Discussion}

The long-term isolation from weaning led to a decrease in amygdalar $\mathrm{D}_{1}$ receptor gene expression in female rats. That represents an original finding as no relevant studies appear to be published previously. The observation of an increase in dopamine $\mathrm{D}_{1}$ receptor expression in the amygdala of adult male mice induced by chronic defeat stress (Huang et al. 2016), a condition very different from the present study design, is not comparable with the present data. The functional consequences of decreased gene expression of $D_{1}$ receptors are unknown. The blockade of dopamine $\mathrm{D}_{1}$ receptors by an infusion of the $\mathrm{D}_{1}$ receptor antagonist SCH 23390 into the amygdala reduced the fear expression in rats (Lamont and Kokkinidis 1998). In a more recent report, dopaminergic blockade by the same $\mathrm{D}_{1}$ receptor antagonist in the central regions of both amygdalas prevented learning related to flavour-taste preference in adult male rats. The effects of the antagonist were abolished by orexin-A administration into the VTA (Risco and Mediavilla 2018). Further studies are needed to be able to relate these findings to neurodevelopmental processes.

The gene expression of dopamine $\mathrm{D}_{2}$ receptors in the amygdala failed to be influenced by stress induced by social isolation. Several recent studies have shown a relationship between amygdalar $\mathrm{D}_{2}$ receptors and behavioural and cognitive functions. In dopamine $\mathrm{D}_{2}$ receptor knockout mice, restora-
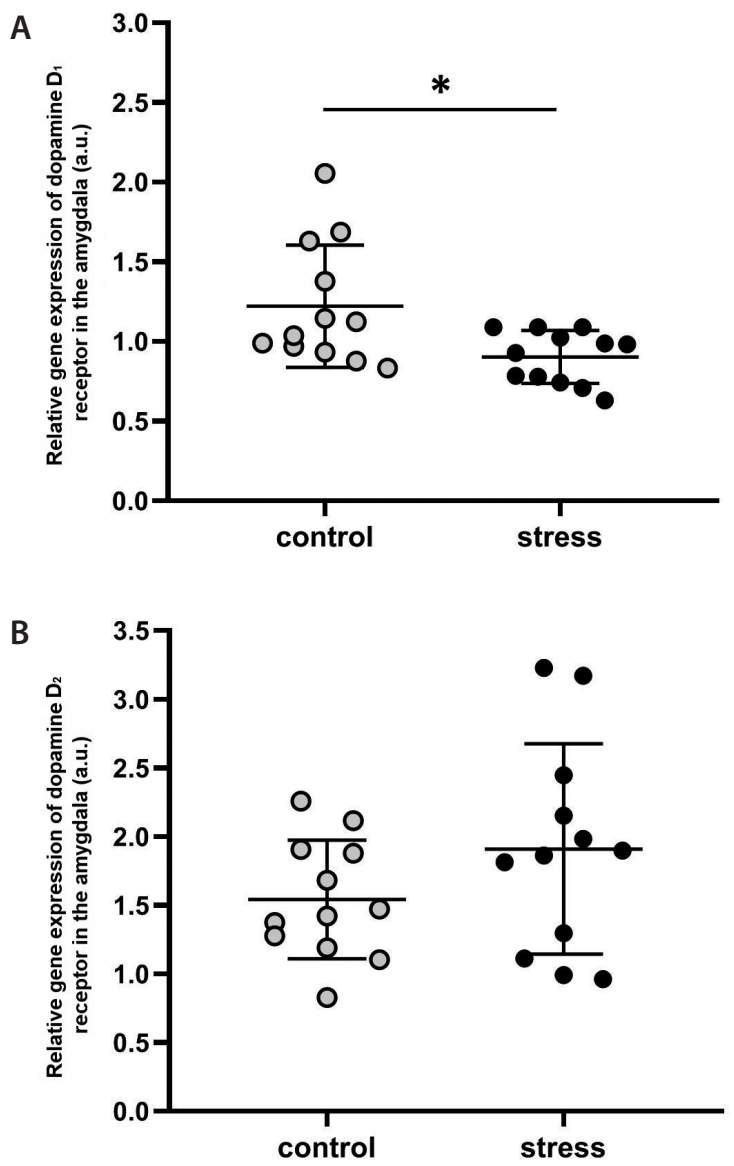

Figure 1. Effect of stress induced by chronic isolation from weaning on amygdalar gene expression of dopamine $\mathrm{D}_{1}$ receptor $(\mathbf{A})$ and dopamine $\mathrm{D}_{2}$ receptor $(\mathbf{B})$. Results are expressed as dot plots with each dot representing an individual subject ( $n=12$ rats per group) with the mean \pm SEM represented by horizontal lines. Statistical analysis was performed by $t$-test for independent groups: ${ }^{\star} p<0.05$. 
tion of $\mathrm{D}_{2}$ receptor gene expression in the central amygdala normalised their enhanced impulsivity (Kim et al. 2018). Experiments with dopamine $\mathrm{D}_{2}$ receptor antagonist and/or agonist infused into the basolateral amygdala revealed that these receptors play a role in fear extinction (Shi et al. 2017) and stress-induced memory impairment (Keshavarzian et al. 2018). The mentioned experiments were performed in male rats. Future studies in female animals are needed to look for potential changes in $\mathrm{D}_{2}$ receptor gene expression in the subregions of the amygdala in response to long-term isolation.

Long-term isolation of rats from weaning resulted in a significant increase in dopamine concentrations in the VTA. This is consistent with the well-established rise in dopamine release from the VTA in animals exposed to acute

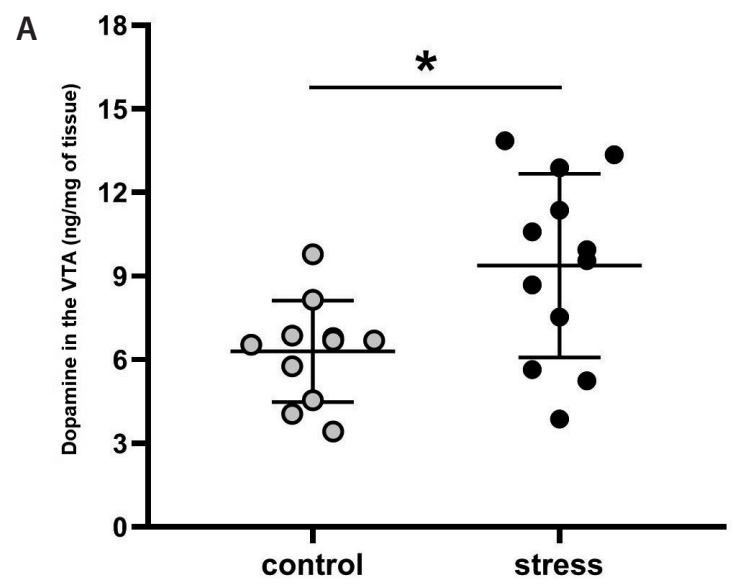

B

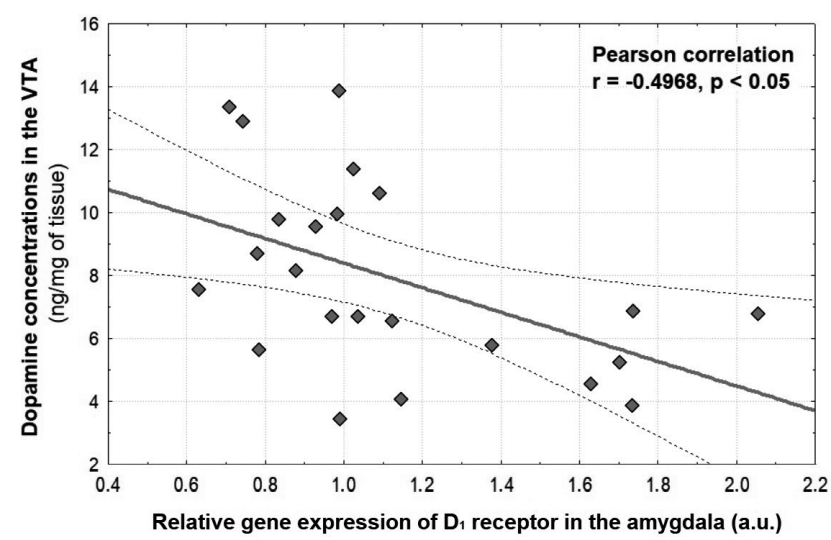

Figure 2. A. Effect of stress induced by chronic isolation from weaning on dopamine concentrations in the VTA. Results are expressed as dot plots with each dot representing an individual subject ( $n=12$ rats per group) with the mean \pm SEM represented by horizontal lines. Statistical analysis was performed by $t$-test for independent groups: ${ }^{*} p<0.05$. B. Negative correlation between the gene expression of dopamine $\mathrm{D}_{1}$ receptor in the amygdala and the dopamine concentrations in the VTA. Statistical significance was evaluated by Pearson analysis. stress stimuli (Holly and Miczek 2016). However, present studies did not use acute stress stimuli. The study by Wang and colleagues (2012) who were working with a similar model of chronic isolation lasting a comparable duration, did not observe any changes in dopamine concentrations in the VTA but they Wistar male rats. We suggest that the enhanced dopamine concentrations found in female rats in this study may be due to an influence of sex and rat strain.

We have observed a negative correlation between amygdalar dopamine receptor $\mathrm{D}_{1}$ gene expression and dopamine concentrations in the VTA, which was particularly evident in rats exposed to stress of chronic isolation. Obviously, this does not imply their causal relationship. We may, however, speculate that chronic isolation affected the pathway from the basolateral amygdala to the dentate gyrus. This pathway was found to be modified by VTA lesion (Abe et al. 2008). Moreover, attenuation of long-term potentiation induced by VTA lesion was restored by dopamine $D_{1}$ and $D_{2}$ receptor agonists injected into the basolateral amygdala (Abe et al. 2009). Functional disconnection of central amygdala from the VTA facilitated associative learning procedures (El-Amamy and Holland 2007). There are few other possible physiological mechanisms, which can be considered based on the published data. $D_{1}$ receptors in the amygdala were shown to modulate neuronal excitability in this brain region (Floresco and Tse 2007). The projections from amygdala into the VTA may primarily reach gama-aminobutyric acid (GABA) rather than dopamine neurons (Beier et al. 2015). It is therefore possible that $\mathrm{D}_{1}$ receptors in the amygdala activate VTA-projecting neurons, which in turn stimulate GABA cells of the VTA, and that finally results in inhibition of dopamine neurons. Consistently, an increase in amygdalar $\mathrm{D}_{1}$ expression may lead to reduced dopamine release in the VTA.

In conclusion, the present study revealed that dopamine $D_{1}$ receptor gene expression in the amygdala was reduced in response to the stress induced by chronic isolation in female rats. This change was accompanied by an increase in dopamine concentration in the VTA. Further studies are needed to understand the physiological significance, if any, of negative association of amygdalar dopamine receptor $\mathrm{D}_{1}$ gene expression and dopamine concentrations in the VTA.

Acknowledgement. This work was supported by the Slovak Research and Development Agency (grant No. APVV-18-0283), and the Scientific Grant Agency of the Ministry of Education, Science, Research and Sports and the Slovak Academy of Sciences (grant No. VEGA 2/0042/19).

\section{References}

Abe K, Niikura Y, Fujimoto T, Akaishi T, Misawa M (2008): Involvement of dopamine D2 receptors in the induction of long-term potentiation in the basolateral amygdala-dentate 
gyrus pathway of anesthetized rats. Neuropharmacology 55, 1419-1424

https://doi.org/10.1016/j.neuropharm.2008.09.005

Abe K, Fujimoto T, Akaishi T, Misawa M (2009): Basolateral amygdala D1- and D2-dopaminergic system promotes the formation of long-term potentiation in the dentate gyrus of anesthetized rats. Prog. Neuropsychopharmacol. Biol. Psychiatry 33, 552-556 https://doi.org/10.1016/j.pnpbp.2009.02.011

Balagova L, Graban J, Puhova A, Jezova D (2019): Opposite effects of voluntary physical exercise on beta3-adrenergic receptors in the white and brown adipose tissue. Horm. Metab. Res. 51, 608-617 https://doi.org/10.1055/a-0928-0758

Bangasser DA, Valentino RJ (2014): Sex differences in stress-related psychiatric disorders: neurobiological perspectives. Front Neuroendocrinol. 35, 303-319 https://doi.org/10.1016/j.yfrne.2014.03.008

Beaulieu JM, Espinoza S, Gainetdinov RR (2015): Dopamine receptors - IUPHAR Review 13. Br. J. Pharmacol. 172, 1-23 https://doi.org/10.1111/bph.12906

Becker JB, Chartoff E (2019): Sex differences in neural mechanisms mediating reward and addiction. Neuropsychopharmacology 44, 166-183 https://doi.org/10.1038/s41386-018-0125-6

Beier KT, Steinberg EE, DeLoach KE, Xie S, Miyamichi K, Schwarz L, Gao XJ, Kremer EJ, Malenka RC, Luo L (2015): Circuit architecture of VTA dopamine neurons revealed by systematic input-output mapping. Cell 162, 622-634 https://doi.org/10.1016/j.cell.2015.07.015

Chmelova M, Balagova L, Marko M, Vrankova S, Cebova M, Jezova D, Riecansky I, Hlavacova N (2019a): Behavioral alterations induced by post-weaning isolation rearing of rats are accompanied by reduced VGF/BDNF/TrkB signaling in the hippocampus. Neurochem. Int. 129, 104473 https://doi.org/10.1016/j.neuint.2019.104473

Chmelova M, Jezova D, Riecansky I, Hlavacova N (2019b): Postweaning social isolation of rats induces reduction in the gene expression of vascular endothelial growth factor (VEGF) in the hippocampus. Gen. Physiol. Biophys. 38, 365-368 https://doi.org/10.4149/gpb_2019019

Csatlosova K, Bogi E, Durisova B, Lacinova L, Jezova D, Dremencov E (2019): Effect of maternal immune activation on the excitability of monoamine neurons in the offspring. Eur. Neuropsychopharmacol. 29, S668

https://doi.org/10.1016/j.euroneuro.2019.01.049

Daskalakis NP, Bagot RC, Parker KJ, Vinkers CH, de Kloet ER (2013): The three-hit concept of vulnerability and resilience: toward understanding adaptation to early-life adversity outcome. Psychoneuroendocrinology 38, 1858-1873 https://doi.org/10.1016/j.psyneuen.2013.06.008

Djouma E, Card K, Lodge DJ, Lawrence AJ (2006): The CRF1 receptor antagonist, antalarmin, reverses isolation-induced up-regulation of dopamine D2 receptors in the amygdala and nucleus accumbens of fawn-hooded rats. Eur. J. Neurosci. 23, 3319-3327 https://doi.org/10.1111/j.1460-9568.2006.04864.x

Douma EH, de Kloet ER (2020): Stress-induced plasticity and functioning of ventral tegmental dopamine neurons. Neurosci. Biobehav. Rev. 108, 48-77 https://doi.org/10.1016/j.neubiorev.2019.10.015

El-Amamy H, Holland PC (2007): Dissociable effects of disconnecting amygdala central nucleus from the ventral tegmental area or substantia nigra on learned orienting and incentive motivation. Eur. J. Neurosci. 25, 1557-1567 https://doi.org/10.1111/j.1460-9568.2007.05402.x

Floresco SB, Tse MT (2007): Dopaminergic regulation of inhibitory and excitatory transmission in the basolateral amygdalaprefrontal cortical pathway. J. Neurosci. 27, 2045-2057 https://doi.org/10.1523/JNEUROSCI.5474-06.2007

Holly EN, Miczek KA (2016): Ventral tegmental area dopamine revisited: effects of acute and repeated stress. Psychopharmacology (Berl) 233, 163-186 https://doi.org/10.1007/s00213-015-4151-3

Huang GB, Zhao T, Gao XL, Zhang HX, Xu YM, Li H, Lv LX (2016): Effect of chronic social defeat stress on behaviors and dopamine receptor in adult mice. Prog. Neuropsychopharmacol. Biol. Psychiatry 66, 73-79 https://doi.org/10.1016/j.pnpbp.2015.12.002

Jaber M, Robinson SW, Missale C, Caron MG (1996): Dopamine receptors and brain function. Neuropharmacology 35, 1503-1519 https://doi.org/10.1016/S0028-3908(96)00100-1

Keshavarzian E, Ghasemzadeh Z, Rezayof A (2018): The basolateral amygdala dopaminergic system contributes to the improving effect of nicotine on stress-induced memory impairment in rats. Prog. Neuropsychopharmacol. Biol. Psychiatry 86, 30-35 https://doi.org/10.1016/j.pnpbp.2018.05.008

Kim B, Yoon S, Nakajima R, Lee HJ, Lim HJ, Lee YK, Choi JS, Yoon BJ, Augustine GJ, Baik JH (2018): Dopamine D2 receptormediated circuit from the central amygdala to the bed nucleus of the stria terminalis regulates impulsive behavior. Proc. Natl. Acad. Sci. USA 115, E10730-E10739 https://doi.org/10.1073/pnas.1811664115

Kolosowska K, Gawryluk A, Wislowska-Stanek A, Liguz-Lecznar M, Hetmanczyk K, Lugowska A, Sobolewska A, Skorzewska A, Gryz M, Lehner M (2019): Stress changes amphetamine response, D2 receptor expression and epigenetic regulation in low-anxiety rats. Prog. Neuropsychopharmacol. Biol. Psychiatry 93, 256-268 https://doi.org/10.1016/j.pnpbp.2019.04.009

Lamont EW, Kokkinidis L (1998): Infusion of the dopamine D1 receptor antagonist SCH 23390 into the amygdala blocks fear expression in a potentiated startle paradigm. Brain Res. 795, $128-136$ https://doi.org/10.1016/S0006-8993(98)00281-9

Lebedev AA, Loseva IV, Shabanov PD (1995): (The effects of dopaminergic agents on the self-stimulation of the lateral hypothalamus and on dopamine metabolism in the brain of isolated rats with a disrupted ventral tegmental area). Zh. Vyssh. Nerv. Deiat. Im I. P. Pavlova 45, 395-401 (in Russian)

Lehner MH, Karas-Ruszczyk K, Zakrzewska A, Gryz M, WislowskaStanek A, Kolosowska K, Chmielewska N, Skorzewska A, Turzynska D, Sobolewska A, et al. (2018): Chronic stress changes prepulse inhibition after amphetamine challenge: the role of the dopaminergic system. J. Physiol. Pharmacol. 69, 3 https://doi.org/10.26402/jpp.2018.3.15

Rentesi G, Antoniou K, Marselos M, Syrrou M, PapadopoulouDaifoti Z, Konstandi M (2013): Early maternal deprivation- 
induced modifications in the neurobiological, neurochemical and behavioral profile of adult rats. Behav. Brain Res. 244, 29-37

https://doi.org/10.1016/j.bbr.2013.01.040

Risco S, Mediavilla C (2018): Orexin A in the ventral tegmental area enhances saccharin-induced conditioned flavor preference: The role of D1 receptors in central nucleus of amygdala. Behav. Brain Res. 348, 192-200

https://doi.org/10.1016/j.bbr.2018.04.010

Shi YW, Fan BF, Xue L, Wen JL, Zhao H (2017): Regulation of Fear Extinction in the Basolateral Amygdala by Dopamine D2
Receptors Accompanied by Altered GluR1, GluR1-Ser845 and NR2B Levels. Front Behav. Neurosci. 11, 116 https://doi.org/10.3389/fnbeh.2017.00116

Wang YC, Ho UC, Ko MC, Liao CC, Lee LJ (2012): Differential neuronal changes in medial prefrontal cortex, basolateral amygdala and nucleus accumbens after postweaning social isolation. Brain Struct. Funct. 217, 337-351 https://doi.org/10.1007/s00429-011-0355-4

Received: March 9, 2020

Final version accepted: April 17, 2020 